\title{
Left ovarian and renal vein thrombosis after emergency postpartum hysterectomy
}

\author{
Nuno André Barros, ${ }^{1}$ Maria Manuel Torrão, ${ }^{2}$ Manuela Ferreira, ${ }^{2}$ Angelina Pinheiro ${ }^{2}$
}

'Department of Gynecology/ Obstetrics, Hospital de Braga, Braga, Portugal

${ }^{2}$ Centro Hospitalar do Médio Ave, Vila Nova Famalicão, Portugal

\section{Correspondence to} Dr Nuno André Barros, nunobarros@mail.com

Accepted 31 May 2016
CrossMark

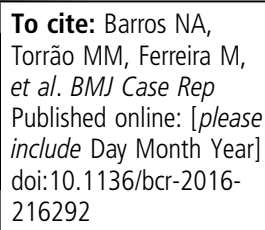

\section{DESCRIPTION}

Both pregnancy and the postpartum period are times characterised by hypercoagulability.

One rare postpartum venous thromboembolic condition is ovarian vein thrombosis, occurring in $0.05-0.2 \%$ of all pregnancies. ${ }^{1}$ The right side is mostly affected, accounting for $80-90 \%$ of all cases. Ovarian vein thrombosis mainly presents with abdominal pain and fever. The differential diagnosis includes pelvic septic thrombophlebitis, adnexal torsion and renal obstruction. ${ }^{2}$ The early diagnosis is imperative to avoid the morbidity and mortality associated with ovarian vein thrombosis. ${ }^{3}$

We report a case of a 38-year-old woman who presented with severe postpartum vaginal haemorrhage due to uterine atony after the uneventful vaginal delivery of a healthy female infant. A total postpartum hysterectomy with conservation of adnexa was performed.

Twelve days after delivery, the patient presented to the emergency department, with severe lower

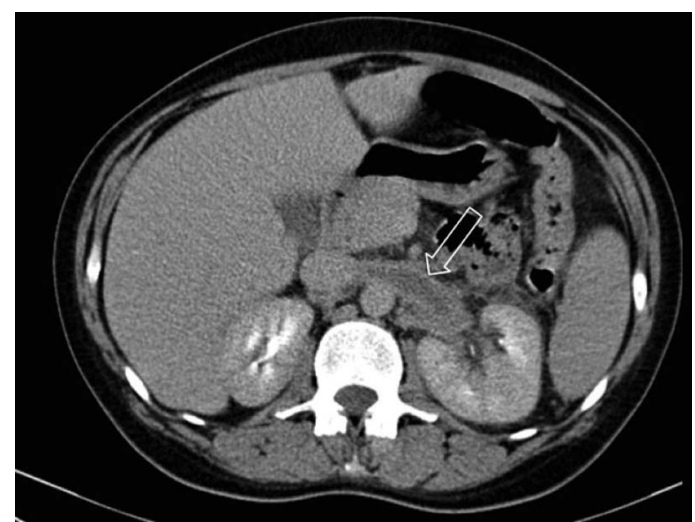

Figure 1 Abdominopelvic CT scan: left renal vein thrombosis (white arrow/transverse plane).

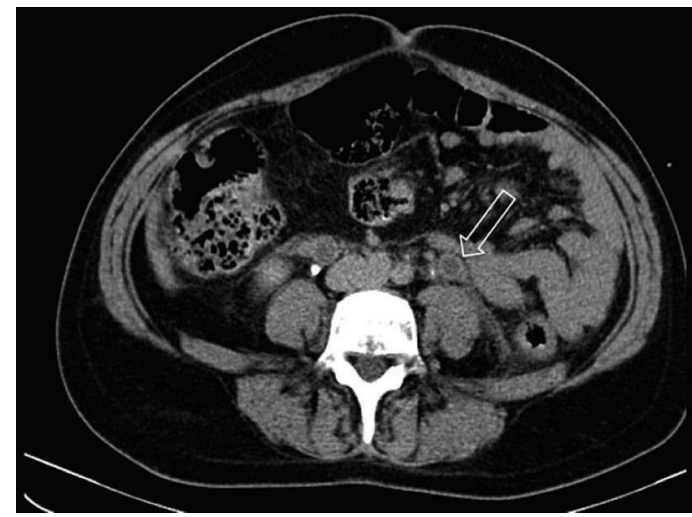

Figure 2 Abdominopelvic CT scan: left ovarian vein thrombosis (white arrow/transverse plane). back pain. She had neither fever nor abdominal pain. Diagnosis of left ovarian and renal vein thrombosis was made after carrying out an abdominal CT (figures 1-3), and treatment with low-molecular-weight heparin (LMWH) was started. After 72 hours, the patient was switched from LMWH to oral anticoagulant treatment. Within 6 days, she was completely asymptomatic and discharged from hospital. After 6 months, a complete recanalisation was demonstrated by abdominal CT (figures 4 and 5).

This is a report of a rare case of postpartum left ovarian and renal vein thrombosis with an unusual presentation. Symptoms of persistent back pain after delivery should lead to the exclusion of this rare condition.

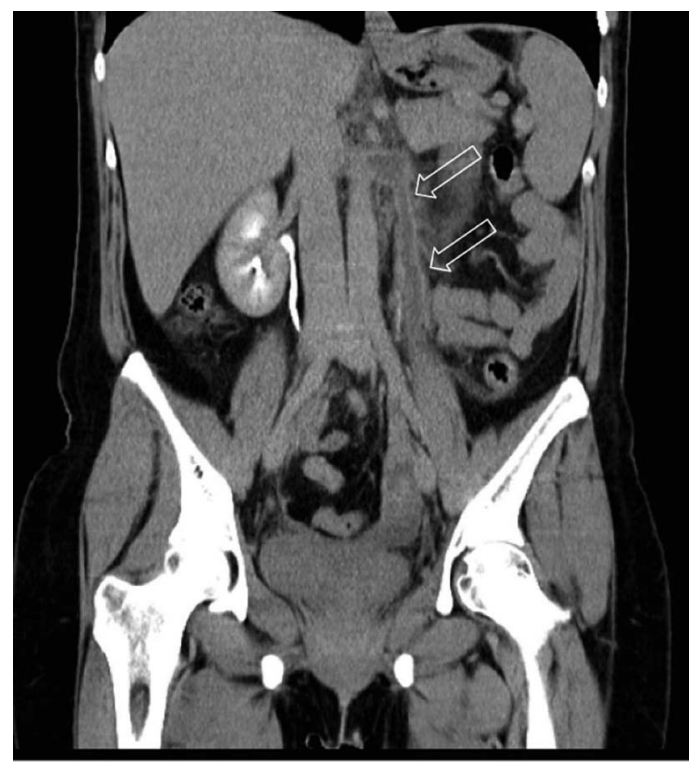

Figure 3 Abdominopelvic CT scan: left ovarian and renal vein thrombosis (white arrows/coronal plane).

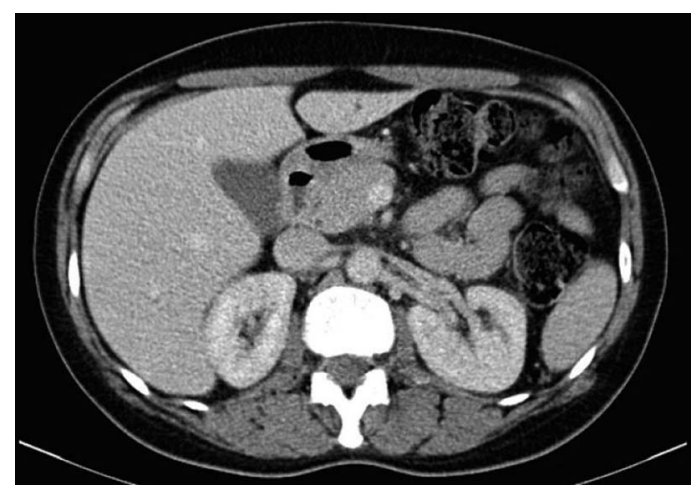

Figure 4 Abdominopelvic CT scan: left renal vein after recanalisation (transverse plane). 


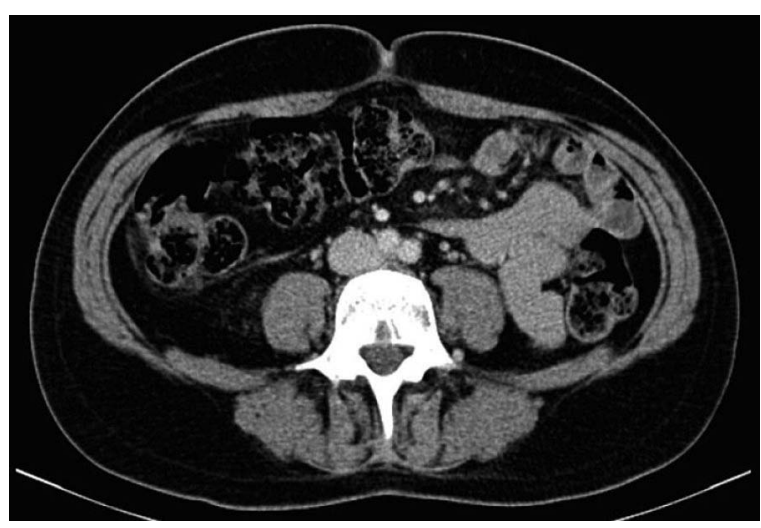

Figure 5 Abdominopelvic CT scan: left ovarian vein after recanalisation (transverse plane).

\section{Learning points}

Postpartum ovarian and renal vein thrombosis can present solely with lower back pain.

- Modern imaging methods, such as CT, are crucial in the diagnosis and follow-up of this condition.

- Low-molecular-weight heparin and oral anticoagulants appear to be components of a rapid and effective treatment.
Acknowledgements The authors would like to acknowledge the collaboration of the Department of Radiology from the Centro Hospitalar do Médio Ave.

Contributors $N A B$ and MMT followed up the patient in the outpatient clinic. MMT, MF and AP evaluated the patient. NAB collected the data and wrote the manuscript. All the authors were involved in the conception of the work and revised it critically for important intellectual content as well. All authors approved the final version to be submitted/published.

Competing interests None declared.

\section{Patient consent Obtained.}

Provenance and peer review Not commissioned; externally peer reviewed.

\section{REFERENCES}

1 Salomon O, Apter S, Shaham D, et al. Risk factors associated with postpartum ovarian vein thrombosis. Thromb Haemost 1999;82:1015-19.

2 Kominiarek MA, Hibbard JU. Postpartum ovarian vein thrombosis: an update. Obstet Gynecol Surv 2006;61:337-42.

3 Liu S, Wen J. Ovarian vein thrombosis with involvement of the renal vein after cesarean section. A case report. J Reprod Med 2015;60:269-72.

Copyright 2016 BMJ Publishing Group. All rights reserved. For permission to reuse any of this content visit http://group.bmj.com/group/rights-licensing/permissions.

BMJ Case Report Fellows may re-use this article for personal use and teaching without any further permission.

Become a Fellow of BMJ Case Reports today and you can:

- Submit as many cases as you like

- Enjoy fast sympathetic peer review and rapid publication of accepted articles

- Access all the published articles

- Re-use any of the published material for personal use and teaching without further permission

For information on Institutional Fellowships contact consortiasales@bmjgroup.com

Visit casereports.bmj.com for more articles like this and to become a Fellow 